Session 2366

\title{
Data acquisition in the dorm room: Teaching experimentation techniques using LEGO Materials
}

\author{
Chris Rogers, Merredith Portsmore \\ Tufts University
}

\begin{abstract}
Data acquisition and analysis concepts taught in introductory courses in experimentation are most effectively learned by engaging students in hands-on activities. Traditional laboratories are usually available on a limited basis to students due to supervision and hardware restrictions. We selected a set of LEGO materials to enable students in our experimental methods course to perform hands-on activities whenever and wherever they want. The fundamental components of this set of materials are the LEGO RCX, a programmable LEGO brick, with the ability to store 2000 points at up to $180 \mathrm{~Hz}$ and LabVIEW Student Edition. These materials, along with a set of sensors, motors, and building components, are given to students at the beginning of the semester. The hardware, the RCX and LEGO elements, is small, portable, and relatively inexpensive allowing students to use and program it in their dorm room using LabVIEW on their own computer. Projects have ranged from characterizing a spring to building and configuring a scanner. Labs addressed topics ranging from repeatability and uncertainty to Hooke's law and Fourier transforms. Eliminating the traditional lab has allowed students more freedom in completing their assignments and allowed more hands-on challenges to be assigned. As a result, class time spent addressing data analysis. The course also addresses effective writing and presentation issues through in class and peer reviews of work.
\end{abstract}

\section{Introduction}

In order for students to truly understand the physics concepts typically taught in junior-level engineering classes (fluid mechanics, heat transfer, thermodynamics, vibrations, ...), they need to touch and feel. Seeing water accelerate through a contraction or the damped vibration of a beam gives them a better understanding of the physics as well as motivation to learn the physics. Unfortunately, laboratory experiences are costly to setup and maintain - both in dollars and in 
instructor time. As a result, classes often lack the hands-on component or have the student follows a prescribed recipe with the goal of completing the lab as soon as possible. We wanted to give the student the necessary hands-on experience and the freedom to design the experiment from scratch. This freedom gives students a better understanding of why they are doing the lab and what it needs to accomplish. It does, however, substantially increase the time and effort the student puts into the lab. Further, it requires the student to have some experience in experiment design. To give junior year students the necessary skills and experience we started a required course at Tufts University in the sophomore year that lasts for $1 / 2$ a semester and teaches experimental methods. It teaches students how to design an experiment, how to use computer control, how to analyze the results of an experiment, and how to present their findings in oral and written formats.

Where a typical course in engineering requires students to setup and solve mathematical equations for homework using textbooks, calculators, and pencils, this course requires students to setup and analyze an experiment. We therefore looked for a hardware and software tool set that would allow the student to perform this homework at home rather than in a laboratory, making these truly homework assignments. We choose LabVIEW as the software platform and the LEGO RCX as the hardware platform for a number of reasons. First, both are relatively cheap, allowing small groups of students to take the materials home. Second, both are fairly simple to learn making it easy to get students up and running quickly. Third, both software and hardware have more capability than the students will need, allowing them to extend their knowledge in future classes. The students are also very enthusiastic about using the LEGO materials. The real goal of the course is to teach students about sampling theory, the use of power spectra, elementary statistics, and presentation skills; the LEGO bricks provide much of the motivation and are easy to use. In the following paper, we outline the course and how it works. We show a number of example laboratory assignments and sample results. Finally, we show how kindergartners and college seniors have used the same tool set to solve various problems..

\section{The Tool Set}

\section{LabVIEW: The Software}

LabVIEW $^{\mathrm{TM}}$ is a commercially available data acquisition and analysis package developed by National Instruments. It is a very powerful analysis tool, allowing everything from image processing to advanced filtering with just a few mouse clicks. It is far more powerful than what the students need for their sophomore or junior year. LabVIEW is one of the most popular industrial analysis packages and has been used for everything from making beer to the Mars

mission. ${ }^{1}$ A number of our students have been hired specifically for their skill in using the package. We are still working on ways of improving the ease-of-entry into the software to 
minimize the programming frustration and maximize the time the students spend thinking about their data.

\section{The RCX: The Hardware}

The RCX is a LEGO brick with an imbedded microcontroller (Figure 1). It has a 10 bit A/D (multiplexed into three channels) capable of measuring voltages from 0 to 5 Volts with an accuracy of $5 \mathrm{mV}$. LEGO makes a number of sensors that work with the RCX, including ones that measure temperature, light, and rotation. Other companies and independent developers have created more sensors for use with the RCX as well ${ }^{2,3}$ The RCX has four $10 \mathrm{msec}$ resolution timers and 3 pulse-width modulated outputs that can control motors, lights and other devices. It was originally intended for robotics but its capability of logging up to 2000 data points makes it a versatile data logger as well. Because it has the robotic capability, students can integrate the data logger directly into an experiment. For instance, they can build a LEGO boat that floats out to the middle of a lake, drops a $\mathrm{pH}$ sensor into the pond and measures the pond $\mathrm{pH}$ and temperature for a few hours and then returns to shore. Some students have mounted accelerometers on the RCX and threw it across the room. As it sailed through the air

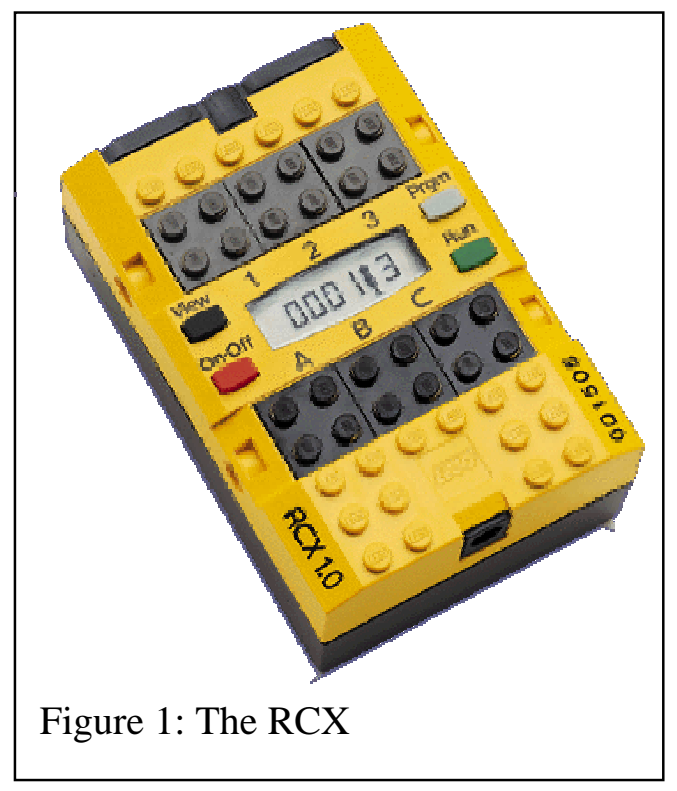
it continually measured its own acceleration, allowing the students to estimate drag coefficients.

\section{Where and what to buy}

National Instruments (makers of LabVIEW) sell a student version of the commercial software that has all the capability students will ever need. LEGO sells two different versions of the RCX. The first is with LEGO software (at Toys R Us) and the second its through their educational division, LEGO Dacta. The material from Dacta has three distinct advantages: 1. The driver software (ROBOLAB) is all written in LabVIEW and is easily ported into the LabVIEW student version, (2) the RCX has an AC plug adapter - necessary for taking data over long time intervals, and (3) they have accompanying curriculum (developed primarily for the elementary school). They sell a number of different kits through Pitsco-Lego Dacta (http://www.pitsco-legodacta.com). We have found that the Robotics Invention Kit works the best - with the only limitation is that one needs to purchase the temperature and angle sensors separately, along with a number of LEGO people (students cannot build an experiment without at least one LEGO person). We actually remove a number of the pieces from these kits before giving them to the students because otherwise the students spend too much time building and too little time thinking about the data. 


\section{ME 1: Introduction to Mechanical Engineering}

ME 1 is a semester long sophomore course that is broken up into two sections, the first half of the course is on experimentation and is the basis of this article. The second half is on machining skills and will not be covered here. The students then use these two skills in the junior year in design courses and in the laboratory components of the standard engineering science courses. Figure 2 outlines the syllabus of the course; the course is taught Wednesdays and Thursdays for 1.5 hours. Wednesday is in a computer lab learning LabVIEW skills with an "electronic workshop" and Thursday is in a classroom learning theory.

\begin{tabular}{|c|c|c|c|c|}
\hline Week & Wednesday & Thursday & Lab Due & Goal \\
\hline 1 & $\begin{array}{l}\text { Introduction } \\
\text { to RCX and } \\
\text { LabVIEW }\end{array}$ & $\begin{array}{l}\text { Sampling Theory, } \\
\text { Simple statistics, } \\
\text { digital vs. analog, } \\
\text { triggers and clocks }\end{array}$ & & $\begin{array}{l}\text { learn to run a } \\
\text { LabVIEW program } \\
\text { and sample an } \\
\text { event. }\end{array}$ \\
\hline 2 & $\begin{array}{l}\text { Arrays, } \\
\text { graphs, and } \\
\text { DAQ }\end{array}$ & $\begin{array}{l}\text { Writeups and } \\
\text { presentations. } \\
\text { Histograms and } \\
\text { more statistics }\end{array}$ & $\begin{array}{l}\text { Response } \\
\text { time }\end{array}$ & $\begin{array}{l}\text { modify existing } \\
\text { programs, to start } \\
\text { thinking about what } \\
\text { you want to measure }\end{array}$ \\
\hline 3 & $\begin{array}{l}\text { Loops and } \\
\text { user IO }\end{array}$ & $\begin{array}{l}\text { Uncertainty } \\
\text { analysis, linear } \\
\text { regression, filtering }\end{array}$ & Spring lab & $\begin{array}{l}\text { learn the need for } \\
\text { uncertainty analysis }\end{array}$ \\
\hline 4 & $\begin{array}{l}\text { Filtering and } \\
\text { regression }\end{array}$ & $\begin{array}{l}\text { Frequency analysis } \\
\text { and more filtering }\end{array}$ & Car lab & $\begin{array}{l}\text { introduce the } \\
\text { concepts of } \\
\text { frequency analysis }\end{array}$ \\
\hline 5 & $\begin{array}{l}\text { More loops } \\
\text { and 2-D data }\end{array}$ & $\begin{array}{l}\text { Sensors and } \\
\text { associated } \\
\text { electronics, } \\
\text { including pulse } \\
\text { width modulation }\end{array}$ & Spring II & $\begin{array}{l}\text { understand how all } \\
\text { the parts work } \\
\text { together to get the } \\
\text { data }\end{array}$ \\
\hline 6 & HOLIDAY & Presentations & Scanner I & $\begin{array}{l}\text { learn from seeing } \\
\text { other presentations }\end{array}$ \\
\hline 7 & $\begin{array}{l}\text { 2D data, } \\
\text { subroutines, } \\
\text { and other } \\
\text { advanced stuff }\end{array}$ & $\begin{array}{l}\text { A/D, DACs, Serial } \\
\text { protocol }\end{array}$ & Scanner II & $\begin{array}{l}\text { show where they } \\
\text { can go }\end{array}$ \\
\hline
\end{tabular}

Figure 2: Class Syllabus

Electronic Workshops

Proceedings of the 2001 American Society of Engineering Education Annual Conference and Exhibition Copyright (C) 2001, American Society of Engineering Education 
The greatest difficulty we have had in the course is teaching programming skills. There is a wide variation in student computer skills and abilities. Because of this we developed web-based instruction that allows each student to progress at his/her own rate both in class (on Wednesday) and at home. We supply ample support through instructor and teaching assistant time.

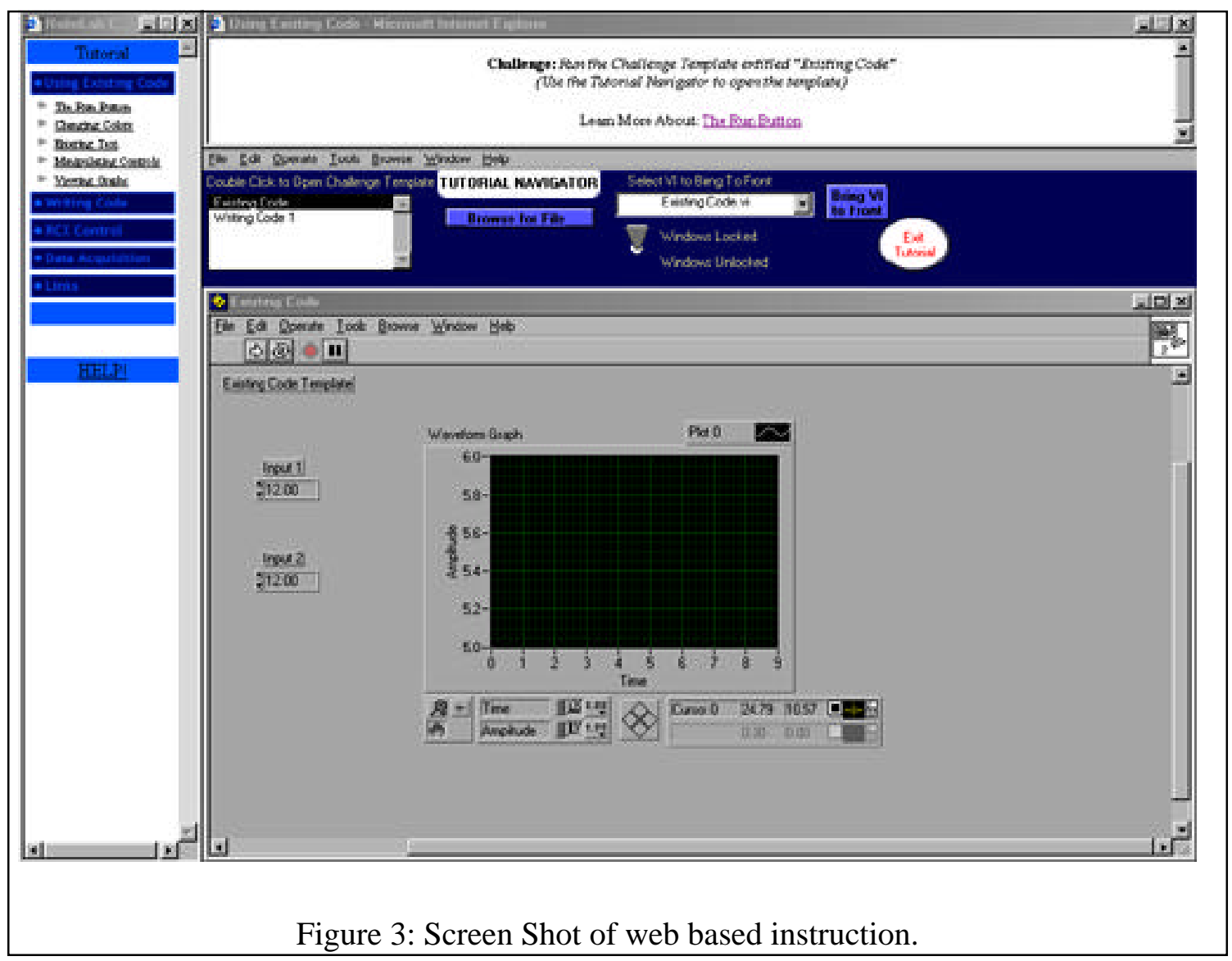

The web-based instruction is accomplished by providing web pages that wrap around the LabVIEW software (Figure 3). The web pages present the students with challenges to complete. Each challenge focuses on different aspects of course including basic use of the LabVIEW software, simple programming, and data topics. Basic use and programming challenges include tasks like "Manipulate the controls on the front panel to alter your graph output" or "Generate a sine wave with an amplitude of 2". Data challenges focus more on understanding how to use the software to perform acquisition and analysis ranging from simple means and standard deviations to Fourier transforms and filtering. Each challenge has links to information, examples, and movies that can help the student complete the task. The challenge/linked information format was developed so that students could get as much or as little information as they needed to help them solve the challenge. This helps accommodate different rates of learning as well as different 
learning styles. The students who need step by step directions are satisfied as well as those who would prefer to tinker with the software on their own and only use help as a last resort.

\section{Programming and Hardware Approach}

The other difficulty we have had is students spending too much time programming instead of analyzing data. Therefore the students start with software that emulates existing hardware tools. Figure 4 shows the oscilloscope front panel. Using the oscilloscope, students can vary the sampling rate and see the effect it has on the resulting waveform. They also start to get a feel for using LabVIEW and can look at the diagram, or code, to understand how to write their own programs. Figure 5 shows the diagram of the oscilloscope panel. Notice that

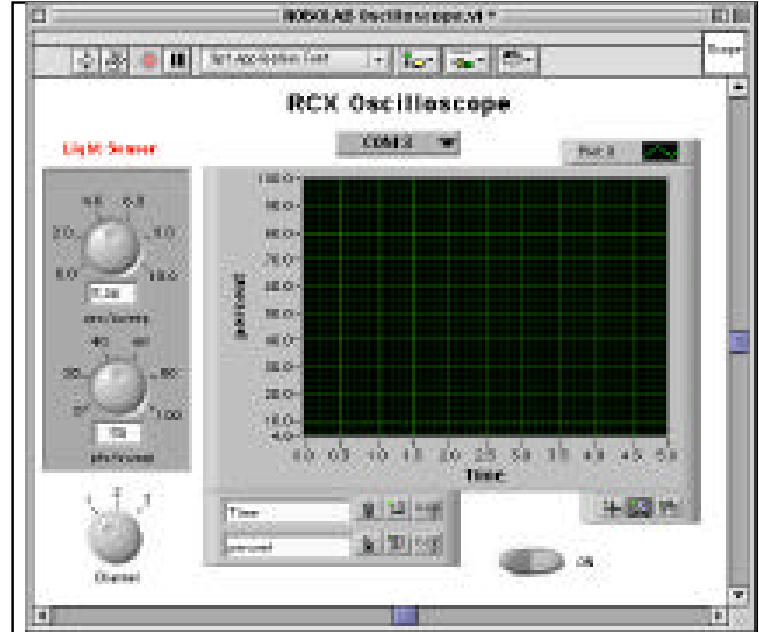

Figure 4: The RCX scope the program is completely graphical. This makes programming and debugging substantially easier. The first part checks to see if the user made any changes to the front panel (new sampling rate etc). If they did then the RCX is reconfigured to reflect those changes; otherwise the program continually reads the data from the RCX and updates the graph on the front panel.

After the students have completed their first lab using existing code, the next experiment requires them to make some modifications of the existing code, bringing in issues of triggering and external clocking. Each lab is designed to add a little more complexity to their code, yet always building off of what they have already done. In the end, their final code is fairly complex and has much of the analysis integrated into it so that they can grab the plots straight from LabVIEW and place them directly into their final report and presentation.

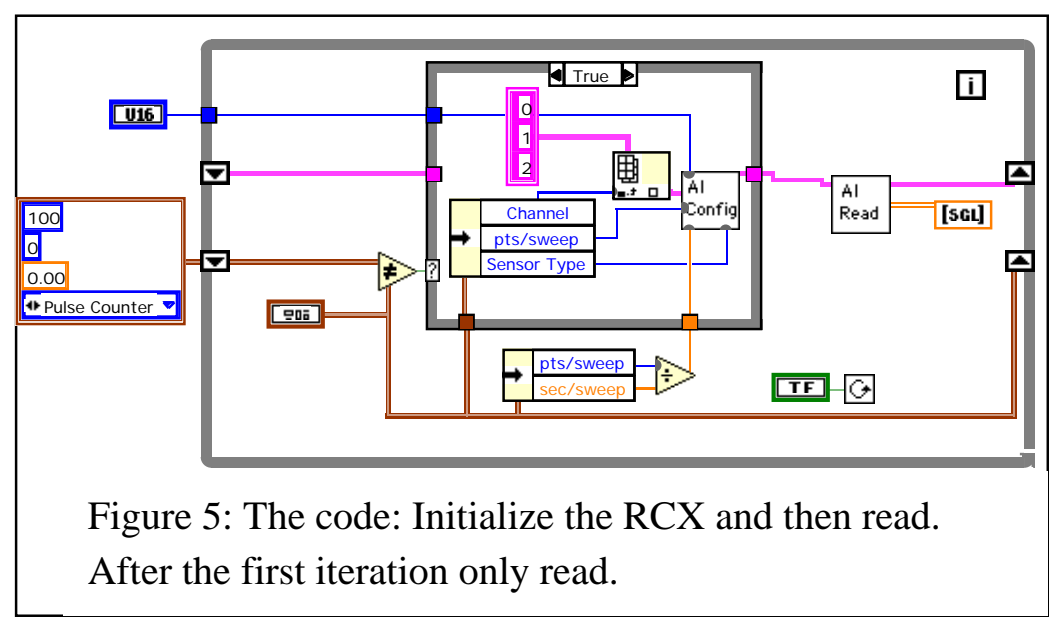

Similar to the software, we have tried to give the students experiments where the LEGO construction time is short. Again, because we want to stress the analysis not the construction. The first few labs have essentially no construction; they require only a sensor and the RCX. The 
car lab is the first time that the students can have fun building and then the final (scanner) lab actually has some construction challenges. In the past, this lab has been the most popular, with students putting in countless hours to have the "coolest" scanner in the class.

\section{The Laboratory Experiences}

Because this course lasts only half a semester, we have 6 labs. The labs are completed at the students' own discretion, there are no formal lab sessions. Students often work in university computer facilities or in their dorm room on the labs. This frees up instructor and teaching assistant time, though both are available at designated times to assist students with questions. The students' frustration level also seems lower as they can manage their own time and resources.

Each lab adds complexity on to the previous labs and the students are required to only hand in their results with a single paragraph discussion (with the exception of the spring lab, which is a full report). The goal of the first lab is to introduce the concept of data acquisition, including sampling rates and triggering. The idea is to develop a reaction time tester - how quickly can a user hit a button after the light comes on. In this case they run an existing code (the oscilloscope code in figure 3). The RCX turns a light on at random intervals and the students sample the touch sensor and even intervals. They discover the difficulty of capturing a random event (the hitting of the switch) with even time sampling and therefore instead sample one of the internal timers in the RCX, using the switch as an external clocking source. Their report is simply a discussion of the two methods along with plots of their reaction times. All plots in the course are required to be in LabVIEW to keep the students using the software.

In the spring lab, students measure the spring constant of a given spring. This lab requires only a spring, an RCX, and a light sensor (see Figure 6). As the RCX bounces on the spring, the light sensor measures its location by the reflection of a light on the ground. Since students can design their own experiments, some did it differently. They had a black and white piece of paper along the axis of the spring so that the light sensor acted as a binary counter - either seeing the white or the black part of the paper as it bounced. At this point in the semester the students only run a few cases and count peaks to determine the natural frequency of the spring. They have to modify the oscilloscope program do to the peak counting

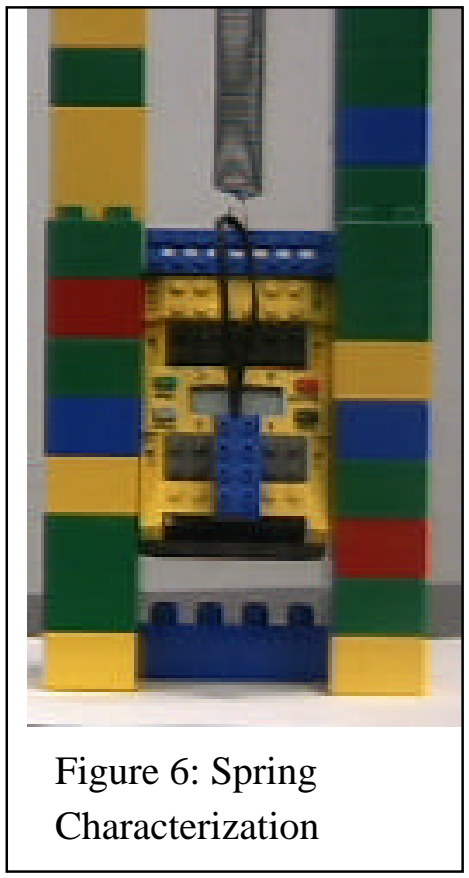
(simply adding one existing subroutine - or subVI - to the program). This lab requires a full journal-style report. 
In the third lab they perform a calibration and an uncertainty analysis. The idea is to have an inclass competition where each group is given a distance and they must program their car (Figure 7) to go that distance by turning motors on for the appropriate amount of time. The amount of time is highly dependent on the car construction and battery power - making the results different for each group. The winner is the one whose car comes closest to the prescribed distance. They can use the oscilloscope program to calibrate their car by measuring an angle sensor while the car is moving. They must modify this program to vary the driving time of the car and plot the total distance (in meters) traveled. They hand in only their calibration plot with an analysis of the repeatability and the accuracy of their calibration.

The fourth lab is the spring lab revisited. This time the students must complete multiple runs to get an uncertainty estimate of their results.

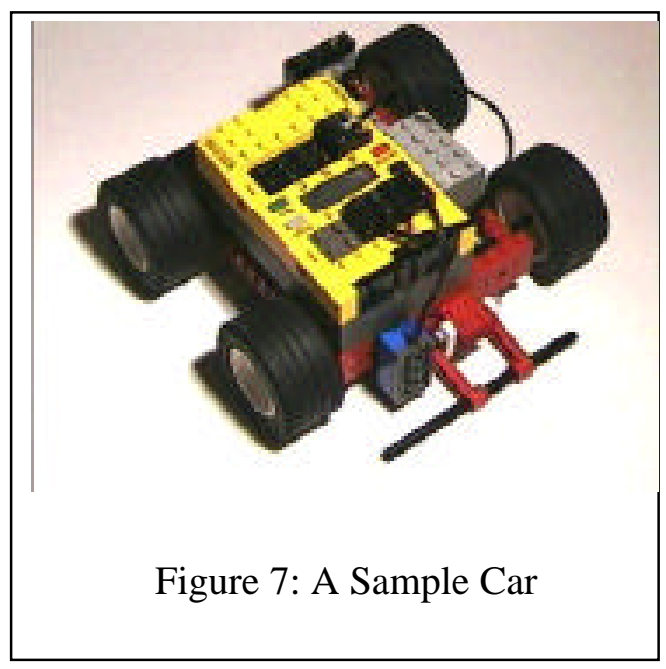

Furthermore, they must modify their previous code so that they can now use the Fourier transform to find the maximum frequency. This gives them an introduction to frequency analysis. They use this new data set in their second draft of their report.

Finally, the last two weeks are two parts of the same lab: to make a scanner. The first week, they must make a simple 1-D scanner by moving the light sensor across a piece of paper while making light readings. Again they can do this with a simple modification of the oscilloscope program. The greater difficulty comes in the second week when they have to traverse the light sensor in two dimensions. This gives them a fairly difficult challenge for the end of the class and introduces them to 2D data sets and simple image processing (to clean up their results). This is usually the most popular lab with the students since the final product includes a fair amount of building. For the last lab, we allow groups to merge resources, going from two students to four students. Some of the final scanners are quite ingenious and inventive. Many move the paper instead of the sensor or some combination of the two.

\section{Communication Skills}

We spend a fair amount of time stressing the importance of communication of results in the class, both through writing and presentations. We have teamed the class with the Reading, Writing, and Thinking Center at Tufts University. The Center trains top students from the past year on not only how to write but also on how to help others with their writing. These students then mentor the current students in their writing. Unfortunately, engineering students at Tufts 
get very little exposure to writing and consequently need a fair amount of help in this area. We have them write up a single lab three times (the spring lab). The first time they write it up, they exchange reports and grade each other according to a supplied 5 page grading sheet. The grading sheet is simply a number of multiple choice questions such as: Did the abstract reflect the work presented?, or Did the student adequately quantify his/her uncertainty?. The next round is with the student mentors and then the final (third) draft gets handed in. Previously we had them write reports for each lab but the workload became too great and we found instead that the multiple draft approach got the same message across with a smaller workload. During the complete writing process, the student mentors handle much of the instruction and assistance, allowing for more individual attention.

The second component (and arguably more important) of the communication part is the presentations. Students are much more willing to give the presentations than to write the reports and therefore often do a substantially better job. They learn how to make a PowerPoint presentation and then are required to present to the rest of the class one of their labs. We stress the importance of simple, legible slides, eye contact, and various marketing tricks to keep audience interest. The six tricks we have found useful are:

1. Count on one slide a minute - more is too fast (lose people) and less is boring. 2. No slide should have sentences or paragraphs. Instead use short phrases (no more than one line long).

3. Pictures are a good thing and fancy transitions and animations are not. People prefer to see rather than to read.

4. Cue cards do not work - if you forget something do not worry about it - more than likely someone will ask you a question later that will allow you to bring it up. If it was really important it should have been on the slide.

5. Practice by starting at the beginning, then each time you make a mistake go back to the beginning. Even if you never make it through the presentation in the practice, the beginning is strong and in the real presentation that is all you need for your confidence.

6. Look nice, act professional, and remember that if you are bored so is your audience. Keep all coins and keys out of the pockets so that you do not play with them while presenting.

Again students grade each other in this area too, looking for eye contact, smooth talking (no "um" etc.), interesting and clear slides, and overall impressions. This part of the course has always been very successful, with alumni telling us that this was the part of their undergraduate training they have used the most in industry. 


\section{Issues and Difficulties}

The greatest difficulty with the class is that we are trying to cover a lot of areas in a short time (data acquisition, experiment design, computer programming, presentation skills, and elementary statistics and Fourier analysis). Because of this the sophomores often feel the course is a lot of work. The LEGO bricks, however, are exciting enough that they still enjoy the course. The electronic workshops help in improving the teaching of the software, along with the concept of modifying an initial program rather than starting from a blank screen. Students tend to learn best by looking at examples, and the workshops present them with a large number of them.

\section{Conclusions and Future Directions}

The LEGO hardware and the LabVIEW software present a universal tool box for introducing the concepts of experiment design. They are versatile enough to satisfy all of our needs and allow us to change the projects every year without purchasing new equipment. They also allow us to give experiments as homework assignments rather than have the traditional lab sections. We have found that students tend to put more time and effort into projects that do not have to be completed by a certain time (the end of the lab class). In the future, we plan on incorporating some elementary image processing to the course and increasing the use of these skills in the other engineering courses.

We have already started to use this tool set in a number of other highly popular courses. The most popular being a freshman course in robotics where students participate in a different robotic competition every week (Figure 8) using the LEGO bricks and LabVIEW. We also have had seniors use them for a higher-level robotics course, stressing algorithm development and one graduate

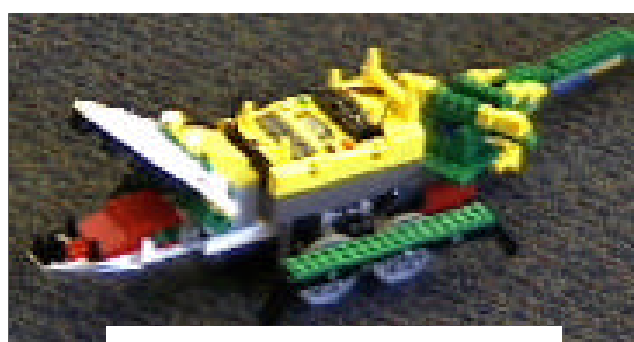

Figure 8: An Alligator student even used them to build a web-controlled drop tower with the LEGO bricks. In the future, we hope to make this toolset like a calculator, something students buy upon entering Tufts, and then use in most of their classes to gain some hands-on experiences in the material.

We also have used the toolset in pre-college education, working with local elementary school students and teachers. The same bricks and software (with a simpler interface) are used by kindergartners to make sure that their LEGO bus stops at each LEGO house before arriving at the school. In the elementary school we have used these tools to teach math (graphing, predicting, pattern recognition, etc.), reading (build what you read), science (measuring and analyzing) and of course engineering. The excitement in the students is universal, transcending age, race, gender, and economic background. We have developed a complete web site with curriculum, more electronic workshops and example competitions at http://www.ceeo.tufts.edu. 


\section{Acknowledgements}

The authors would like to thank the National Science Foundation for the funding of this work

along with LEGO Corp., NASA, and the many teachers and students that have been involved with this project.

Bibliography

1. URL: http://www.ni.com ; National Instruments.

2. Baum, D., Zurcher, R., Dave Baum's Definitive Guide to LEGO Mindstorms. (Technology In Action) 1 APress (1999)

3. URL: http://www.dcpmicro.com ; DCP Microdevelopments Limited

\section{CHRIS ROGERS}

Chris Rogers is an associate professor of Mechanical Engineering at Tufts University. He got all his degrees at Stanford University. He spends much of his time either playing with LEGO bricksor looking at the behavior of particles in a turbulent airflow.

\section{MERREDITH PORTSMORE}

Merredith Portsmore graduated from Tufts University with a BS in Mechanical Engineering and an MA in Education. She is currently a member of the CEEO staff and is constantly developing and teaching new engineering concepts through the web and LEGO bricks.

Proceedings of the 2001 American Society of Engineering Education Annual Conference and Exhibition Copyright (C) 2001, American Society of Engineering Education 